\title{
ABSTRACT The Chair Project: Firmness, Commodity, and an emphasis on Delight
}

This paper will describe the theoretical approach and methodology and show the outcome of a pedagogical experiment that has proven to be highly successful in motivating architecture students to master structural analysis and design. The Chair Project is the term project for the last of the sequence of three required Structures courses in the curriculum of the University of Waterloo School of Architecture. Each student is required to design, construct and structurally analyze a folding or take-apart wooden chair for a specific "client". The choice of his/her client is up to the student, but should be a well-known creative personality who can serve as a term-long inspiration for the design of the chair. By being assigned a small but structurally provocative design-build project as part of their structures coursework, the students are provided with an immediate need-to-know application while they are learning the techniques of structural analysis. The folding wooden chair as a design-build and computational analysis project has the additional benefit of being an object that the students are able to construct, analyze and load-test at full scale.

After completing the construction of the chair, each student performs a thorough computational structural analysis of the chair in its different positions with and without an occupant, making simplifying assumptions as necessary to accommodate the occurrence of static indeterminacy beyond the level of their analytical skills. Course assignments guide the project through all the steps of initial client research, design conceptualization, design development, construction in the woodshop, presentation of the built chair with demonstration of its moving parts, and comprehensive structural analysis. The entire process is documented and assembled into a final project booklet. Throughout, students are encouraged to approach the project with attention to the Vitruvian goals of firmness, commodity and delight, with an emphasis on delight.

Elizabeth C. English ecenglish@uwaterloo.ca
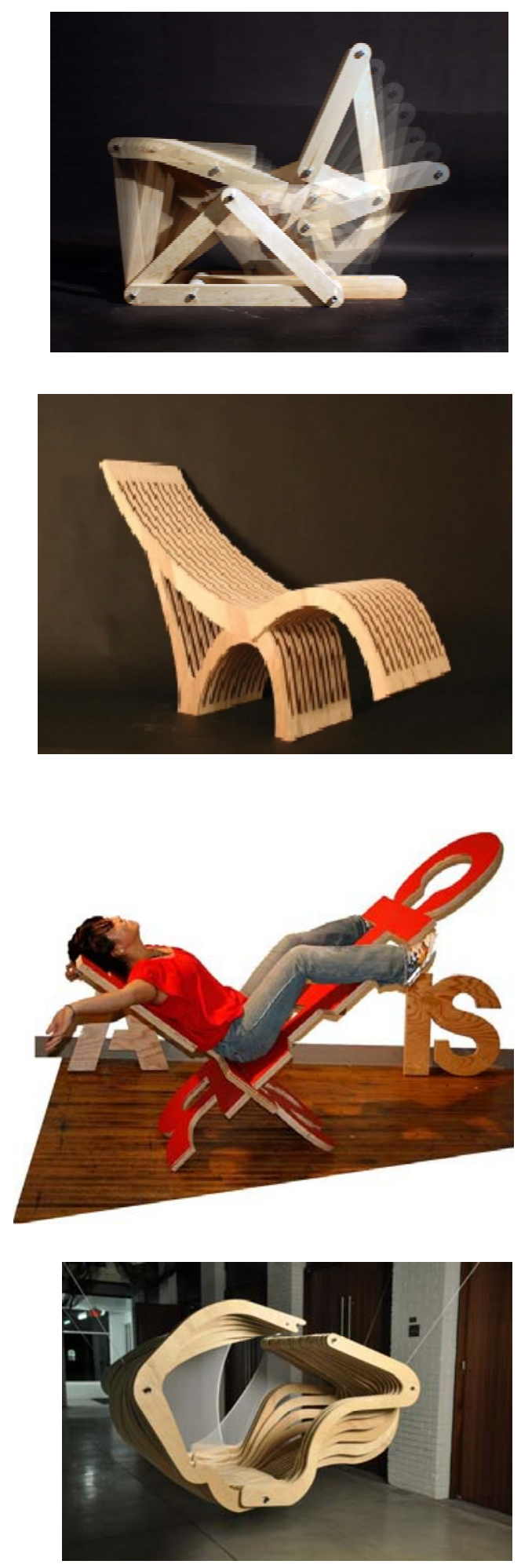